\title{
Descriptive analysis of and overall survival after surgical treatment of lung metastases*
}

\author{
Análise descritiva e sobrevida global do tratamento \\ cirúrgico das metástases pulmonares
}

\author{
Giana Balestro Poletti, Ivan Felizardo Contrera Toro, Thais Ferreira Alves, \\ Eliana Cristina Martins Miranda, José Cláudio Teixeira Seabra, Ricardo Kalaf Mussi
}

\begin{abstract}
Objective: To describe demographic characteristics, surgical results, postoperative complications, and overall survival rates in surgically treated patients with lung metastases. Methods: This was a retrospective analysis of 119 patients who underwent a total of 154 lung metastasis resections between 1997 and 2011. Results: Among the 119 patients, 68 (57.1\%) were male and 108 (90.8\%) were White. The median age was 52 years (range, 15-75 years). In this sample, 63 patients (52.9\%) presented with comorbidities, the most common being systemic arterial hypertension (69.8\%) and diabetes (19.0\%). Primary colorectal tumors (47.9\%) and musculoskeletal tumors $(21.8 \%)$ were the main sites of origin of the metastases. Approximately $24 \%$ of the patients underwent more than one resection of the lesions, and 71\% had adjuvant treatment prior to metastasectomy. The rate of lung metastasis recurrence was 19.3\%, and the median disease-free interval was 23 months. The main surgical access used was thoracotomy (78\%), and the most common approach was wedge resection with segmentectomy (51\%). The rate of postoperative complications was $22 \%$, and perioperative mortality was $1.9 \%$. The overall survival rates at 12,36, 60, and 120 months were 96\%, 77\%, 56\%, and 39\%, respectively. A Cox analysis confirmed that complications within the first 30 postoperative days were associated with poor prognosis (hazard ratio = $1.81 ; 95 \% \mathrm{Cl}: 1.09-3.06 ; \mathrm{p}=0.02$ ). Conclusions: Surgical treatment of lung metastases is safe and effective, with good overall survival, especially in patients with fewer metastases.
\end{abstract}

Keywords: Neoplasm metastasis; Survival analysis; Thoracic surgery; Metastasectomy.

\section{Resumo}

Objetivo: Descrever características demográficas, resultados operatórios, complicações pós-operatórias e taxa de sobrevida global em pacientes com metástases pulmonares tratados cirurgicamente. Métodos: Análise retrospectiva de 119 pacientes submetidos a um total de 154 cirurgias de ressecção de metástase pulmonar entre 1997 e 2011. Resultados: Do total de 119 pacientes, 68 (57,1\%) eram do sexo masculino, e 108 (90,8\%) eram brancos. A mediana de idade foi de 52 anos (variação, 15-75 anos). Nessa amostra, 63 pacientes $(52,9 \%)$ apresentaram comorbidades, sendo as mais frequentes hipertensão arterial sistêmica $(69,8 \%)$ e diabetes $(19,0 \%)$. Tumores primários colorretais $(47,9 \%)$ e musculoesqueléticos $(21,8 \%)$ foram os principais sítios de origem das metástases. Aproximadamente $24 \%$ dos pacientes foram submetidos a mais de uma ressecção das lesões, e $71 \%$ fizeram tratamento adjuvante prévio à metastasectomia. A taxa de recidiva de metástase pulmonar foi de 19,3\%. A mediana do intervalo livre de doença foi de 23 meses. A principal via de acesso usada foi toracotomia (78\%), e o tipo de ressecção mais frequente foi em cunha e segmentectomia (51\%). 0 índice de complicações pós-operatórias foi de $22 \%$ e o de mortalidade perioperatória foi de $1,9 \%$. As taxas de sobrevida global em 12, 36, 60 e 120 meses foram, respectivamente, de 96\%, 77\%, 56\% e 39\%. A análise de Cox confirmou que complicações nos primeiros 30 dias pós-operatórios associaram-se a pior prognóstico (hazard ratio $=1,81$; 1C95\%: 1,09-3,06; $p=0,02$ ). Conclusões: 0 tratamento cirúrgico das metástases pulmonares oriundas de diferentes sítios tumorais é efetivo e seguro, com boa sobrevida global, especialmente nos casos com um menor número de lesões pulmonares.

Descritores: Metástase neoplásica; Análise de sobrevida; Cirurgia torácica; Metastasectomia.

*Study carried out at the Universidade Estadual de Campinas - Unicamp, State University at Campinas - Campinas, Brazil. Correspondence to: Ricardo Kalaf Mussi. Rua Copaíba, 810, Loteamento Alphaville, CEP 13098-347, Campinas, SP, Brasil. Tel. 5519 9771-7646. E-mail: rkalaf@fcm.unicamp.br Financial support: None.

Submitted: 22 January 2013. Accepted, after review: 14 October 2013. 


\section{Introduction}

For many years, the diagnosis of lung metastasis was considered the end stage of the disease course in patients with malignant neoplasms. Initially, the treatment proposed consisted of chemotherapy and hormone therapy, and unsatisfactory responses were seen in more than 70\% of cases $\ln 1882$, Weinlechner incidentally performed the first lung metastasis resection during the resection of a primary tumor, a procedure in which the metastasis was removed en bloc with the surgical specimen. ${ }^{(2)}$ Since then, various other cases of metastasectomy have been reported, many with positive results.

In 1951, Ehrenhaft started selecting candidates for lung metastasis resection, ${ }^{(3)}$ and, subsequently, it was possible to establish well-defined criteria.

Surgical treatment evolved over the 20th century because of greater knowledge about tumors that gave rise to lung metastases only. Surgical treatment of lung metastases has been given a boost in the last 15 years, as has been shown in the literature, and some of the major prognostic factors for this condition, such as disease-free interval and type of resection performed, have been identified,. ${ }^{(4,5)}$ However, in comparison with major centers worldwide, there have been few studies of Brazilian patients and this treatment modality in Brazil.

Therefore, the objective of the present study was to evaluate the results of surgical treatment of lung metastases at a university hospital in the city of Campinas, Brazil.

\section{Methods}

This was a retrospective study using surgical records of the Department of Thoracic Surgery of the State University at Campinas Hospital de Clínicas, located in the city of Campinas, Brazil. We reviewed all records of resection of lung lesions performed in patients with a previous diagnosis of primary cancer in other organs, as well as all records of complete resection of all lesions and pathological confirmation of metastatic disease, between January 1, 1997 and December 31, 2011.

We included all patients with lung lesions who were selected for surgery on the basis of the Thomford et. al. criteria for surgical treatment of metastatic lung lesions, ${ }^{(6)}$ namely: a) complete resection of all metastatic disease should be possible; b) the patient should have sufficient pulmonary function to withstand the risk of surgery and survive the postoperative period; c) the primary tumor should be (or can be) controlled; d) there should be no evidence of extrapulmonary metastases, except for colon tumors; and e) there should be no effective treatment other than surgery.

Pulmonary function was assessed on the basis of arterial blood gas analysis results and pulmonary function test results. If the pulmonary function test was not technically possible, the six-minute walk test, which has been proven to be well tolerated and safe in the assessment of patient functional capacity, was used. ${ }^{(7)}$

In addition, the records were reviewed for the postoperative presence of systemic inflammatory response syndrome (SIRS), which was defined by the presence of at least two of the following parameters, on the same day, within three days after surgery: an axillary temperature above $38^{\circ} \mathrm{C}$; an RR > 24 breaths/min; an HR > 90 bpm; and a leukocyte count greater than 10,000 cells/ $\mathrm{mm}^{3}$ or less than 5,000 cells $/ \mathrm{mm}^{3}$.

Overall survival was defined as the date of first surgery to the last follow-up visit or to death (from any cause). To determine disease-free intervals, we used the dates of primary cancer treatment and the date of referral for thoracic surgery for treatment of lung metastasis.

We designed a data collection form that was used by two trained physicians to obtain the patient medical record information needed to meet the objectives of the present study. This form contained the following fields: patient initials; medical record number; gender; race; date of birth; date of surgery of the primary tumor; date of referral for thoracic surgery; symptoms at diagnosis of metastasis (dyspnea, cough, hemoptysis, and chest pain); smoking; anatomical site of the primary tumor (breast, head, neck, colorectum, kidney, musculoskeletal system, gonads, etc.); presence and type of comorbidity; history of resection for liver metastasis; neoadjuvant or adjuvant therapy to treatment of lung metastasis; number of lung resections; number and location of nodules found intraoperatively; date of resection of the metastasis; type of resection performed (segmentectomy, wedge resection, nodule resection, lobectomy, bilobectomy, and pneumonectomy); use of a stapler; extubation in the operating room; number of chest tubes and side of placement; unilateral or bilateral approach; surgical access 
(thoracotomy, bilateral sequential thoracotomy, sternotomy, and video-assisted surgery); need for blood transfusion; postoperative recovery in the ICU; development of SIRS; length of hospital stay; presence and type of complication within 30 days after surgery; postoperative day of onset of the complication; current status of the patient (alive/dead); date of the last follow-up visit to our facility; and whether follow-up was conducted at another facility.

Data on postoperative complications, defined as any type of event experienced by patients within 30 days after surgery, were extracted from patient medical records. These data were grouped by major system or pathology involved, listed by frequency, and stratified as a variable in the overall survival curve.

The present study was approved by the Research Ethics Committee of the State University at Campinas School of Medical Sciences (Protocol no. 001/2013).

For categorical variables, we conducted an exploratory descriptive analysis and, subsequently, we used Pearson's, Spearman's, and Fisher's tests, whereas, for continuous variables, we used the t-test (two groups) or the Kruskal-Wallis test (more than two groups). In cases with missing data, the valid percent of variables was calculated. The Kaplan-Meier method was used for survival analyses, and the log-rank test was used for survival comparisons. Cox regression analysis (by Wald's backward stepwise method) was performed to identify the predictive variables over time. For univariate and multivariate analyses, the level of significance was set at $p<0.10$ and $p<0.05$, respectively. The analyses were performed with the Statistical Package for the Social Sciences, version 14.0 (SPSS Inc., Chicago, IL, USA).

\section{Results}

During the study period, 119 patients underwent a total of 154 surgical procedures. Among those patients, 68 (57.1\%) were male and $108(90.8 \%)$ were White. The median age was 52 years (range, 15-75 years). The main sites of origin of the primary tumor were the colorectum, in $47.9 \%$ of the patients; the musculoskeletal system, in 21.8\%; the head and neck, in 7.5\%; and the gonads, in 5.9\%. Comorbidities were found in 63 patients (52.9\%), and the most common were systemic arterial hypertension, in 69.8\%; diabetes, in 19.0\%; asthma/COPD, in 7.9\%; dyslipidemia, in 7.9\%; hyperthyroidism, in 6.3\%, and heart disease, in 6.3\%. Some patients had more than one comorbidity. A total of one, two, three, and four surgical procedures, respectively, were performed on 91 (76.5\%), 24 (20.2\%); 3 $(2.5 \%)$, and $1(0.8 \%)$ of the patients. Ten patients (8.4\%) underwent resection for liver metastasis before the diagnosis of lung metastasis. Likewise, 85 patients (71.4\%) underwent chemotherapy and/or radiotherapy before lung metastasis resection. After resection, 88 patients (75.9\%) underwent adjuvant chemotherapy (Table 1). The rate of lung metastasis recurrence was 19.3\%. The median disease-free interval was 23 months (range, 1-172 months).

The mean length of hospital stay was 8 days (range, 3-40 days) for the 154 surgical procedures.

The preferential location of the resected lesions was the left lower lobe (in 24.8\%), followed by the left upper lobe (in 24.4\%) and the right lower lobe (in 21.5\%). A total of 511 lesions were described.

In 25 surgical procedures (16.3\%), bilateral lesions were resected during the same surgical session, whereas, in 129 procedures (83.7\%), only one of the lungs was treated. Of those 129 surgical procedures, 20 (in 10 patients) were performed on average 2 months apart in order to treat bilateral disease, which was present in 35 patients (29.4\%) at diagnosis of lung metastasis.

The most common surgical access was thoracotomy, in $78.6 \%$ of the cases, followed by sternotomy, in $9.1 \%$; bilateral sequential thoracotomy, in 8.5\%; and video-assisted surgery, in 3.8\%. Bilateral thoracotomy, despite consisting of two different access routes, was considered as a single surgical procedure.

The types of resection performed were wedge resection or segmentectomy, in 51.3\% of the cases; nodule resection, in $29.9 \%$; lobectomy or bilobectomy, in 15.6\%; and pneumonectomy, in $3.2 \%$.

In 107 (69.5\%) of a total of 154 surgical procedures, a linear stapler was used to assist in suturing the lung parenchyma.

In 10 procedures (6.5\%), the patients were not extubated in the operating room, and, in 12 (7.8\%), the patients did not recover from the immediate postoperative period in the ICU environment. 
Table 1 - Demographic and clinical characteristics of the 119 study patients.

\begin{tabular}{|c|c|c|}
\hline Variable & $\mathrm{n}$ & $\begin{array}{c}\text { Valid } \\
\% \\
\end{array}$ \\
\hline \multicolumn{3}{|l|}{ Gender } \\
\hline Male & 51 & 57.1 \\
\hline Female & 68 & 42.9 \\
\hline \multicolumn{3}{|l|}{ Race } \\
\hline White & 108 & 90.8 \\
\hline Non-White & 11 & 9.2 \\
\hline \multicolumn{3}{|c|}{ Symptoms at diagnosis of metastasis } \\
\hline Yes & 36 & 30.3 \\
\hline No & 83 & 69.7 \\
\hline \multicolumn{3}{|l|}{ Smoking } \\
\hline Yes & 35 & 29.7 \\
\hline No & 83 & 70.3 \\
\hline \multicolumn{3}{|l|}{ Origin of the primary tumor ${ }^{\mathrm{a}}$} \\
\hline Colorectum & 57 & 47.9 \\
\hline Musculoskeletal system & 26 & 21.8 \\
\hline Head - neck & 09 & 7.5 \\
\hline Gonads & 07 & 5.9 \\
\hline Kidney & 04 & 3.4 \\
\hline Breast & 04 & 3.4 \\
\hline Melanomas & 04 & 3.4 \\
\hline Others & 08 & 6.7 \\
\hline \multicolumn{3}{|l|}{ Surgical procedures } \\
\hline 1 & 91 & 76.5 \\
\hline 2 & 24 & 20.2 \\
\hline 3 & 03 & 2.5 \\
\hline 4 & 01 & 0.8 \\
\hline \multicolumn{3}{|c|}{ History or resection for liver metastasis } \\
\hline Yes & 10 & 8.4 \\
\hline No & 109 & 91.6 \\
\hline \multicolumn{3}{|l|}{ CHT/RT before resection } \\
\hline Yes & 85 & 71.4 \\
\hline No & 34 & 28.6 \\
\hline \multicolumn{3}{|l|}{$\mathrm{CHT} / \mathrm{RT}$ after resection } \\
\hline Yes & 88 & 75.9 \\
\hline No & 28 & 24.1 \\
\hline \multicolumn{3}{|l|}{ Comorbidities } \\
\hline Yes & 63 & 52.9 \\
\hline No & 56 & 47.1 \\
\hline
\end{tabular}

CHT/RT: chemotherapy and/or radiotherapy. ${ }^{\text {aEight missing }}$ cases: endometrial tumor ( 3 cases); ovary tumor ( 1 case); lung tumor ( 1 case); pancreas tumor ( 1 case); liver tumor (1 case); and stomach tumor (1 case).

After the surgical procedures, 28 patients (18.2\%) developed SIRS, and 9 of those patients had some type of perioperative complication.

In the perioperative period, 34 patients $(22.1 \%)$ had some type of complication, the most common being pulmonary conditions (pneumonia, respiratory failure, prolonged mechanical ventilation, retained clot, pulmonary edema, persistent air fistula) in 25 (16.2\%) and extrapulmonary conditions (heart failure, arrhythmia, urinary tract/urinary tract wall infection, and thromboembolism in 12 (7.8\%). In 3 cases, concomitant pulmonary and extrapulmonary complications were found.

Perioperative mortality was 3 patients (1.9\%), 1 of whom died from an irreversible arrhythmia during the procedure and 2 of whom died from pulmonary complications (Table 2).

Of the 119 patients studied, 64 (53.8\%) continued with follow-up treatment, whereas $22(18.5 \%)$ lost contact with the facility for more than 1 year, and 33 (27.7\%) died.

Table 3 shows the overall survival rates of the patients at 12,36, 60, and 120 months, which were $96 \%, 77 \%, 56 \%$, and 39\%, respectively. Overall survival for the groups of patients who underwent and who did not undergo chemotherapy/radiotherapy before surgery (48\% and $72 \%$ ) and after surgery (51\% and $72 \%$ ) showed a significant difference $(p=0.02)$ in favor of those who did not undergo chemotherapy/ radiotherapy, but this was not confirmed in the multivariate analysis. A Cox analysis in which patients with and without complications within the first 30 days after surgery were compared (67\% vs. $24 \% ; p<0.0001)$ confirmed that the former had poor prognosis (hazard ratio $=1.81$; 95\% Cl: 1.09-3.06; $p=0.02$; Figure 1).

Survival stratification by anatomical site of the primary tumor showed that overall survival at 60 months was $68 \%$ for colorectal carcinoma, $26 \%$ for musculoskeletal carcinoma, and 56\% for the other types of tumor (which are less common than the former two; Figure 2).

Survival at 60 months in the patients who had up to 6 lesions resected ranged from $60 \%$ to $76 \%$, whereas, in those who had more than 7 nodules resected, survival at 60 months dropped to $13 \%$. In the patients with bilateral disease at diagnosis, overall survival was $63 \%$, and, in those with unilateral disease, overall survival was 55\%. This difference was not statistically significant.

\section{Discussion}

The present study showed that the population analyzed had characteristics similar to those reported in major studies: there was a slight predominance of males; the histology of the 
Table 2 - Characteristics of the 154 surgical procedures performed during the study period.

\begin{tabular}{|c|c|c|}
\hline Variable & $n$ & $\begin{array}{c}\text { Valid } \\
0 \% \\
\end{array}$ \\
\hline \multicolumn{3}{|l|}{ Type of approach } \\
\hline Unilateral & 129 & 83.7 \\
\hline Bilateral & 25 & 16.3 \\
\hline \multicolumn{3}{|l|}{ Preferential location of the nodules } \\
\hline LLL & 126 & 24.8 \\
\hline LUL & 125 & 24.4 \\
\hline RLL & 110 & 21.5 \\
\hline RUL & 97 & 19.0 \\
\hline \multicolumn{3}{|l|}{ Surgical access } \\
\hline Thoracotomy & 121 & 78.6 \\
\hline Bilateral thoracotomy & 13 & 8.5 \\
\hline Sternotomy & 14 & 9.1 \\
\hline Video-assisted surgery & 06 & 3.8 \\
\hline \multicolumn{3}{|l|}{ Most common resection performed } \\
\hline Wedge resection + segmentectomy & 79 & 51.3 \\
\hline Nodule resection & 46 & 29.9 \\
\hline Lobectomy + bilobectomy & 24 & 15.6 \\
\hline Pneumonectomy & 05 & 3.2 \\
\hline \multicolumn{3}{|l|}{ Mechanical suture or linear stapler } \\
\hline Yes & 107 & 69.5 \\
\hline No & 47 & 30.5 \\
\hline \multicolumn{3}{|l|}{ Extubation in the operating room } \\
\hline Yes & 144 & 93.5 \\
\hline No & 10 & 6.5 \\
\hline \multicolumn{3}{|l|}{ Recovery in the ICU } \\
\hline Yes & 142 & 92.2 \\
\hline No & 12 & 7.8 \\
\hline \multicolumn{3}{|l|}{ SIRS } \\
\hline Yes & 28 & 18.2 \\
\hline No & 126 & 81.8 \\
\hline \multicolumn{3}{|c|}{ Complication within the first 30 days after surgery } \\
\hline Yes & 34 & 22.1 \\
\hline No & 120 & 77.9 \\
\hline
\end{tabular}

LLL: left lower lobe; LUL: left upper lobe; RLL: right lower lobe; RUL: right upper lobe; and SIRS: systemic inflammatory response syndrome.

primary tumor was predominantly colorectal adenocarcinoma; and there was approximately $30 \%$ of bilaterality of disease at diagnosis of lung metastasis. ${ }^{(8)}$

The most common surgical access in all studies is thoracotomy, and there have been few reports of treatment of the two lungs during the same surgical procedure. ${ }^{(9-12)}$ In such cases, we preferentially choose sternotomy; however, depending on the location of the lesion, bilateral thoracotomy may be the best alternative. The
Table 3 - 0verall survival data.

\begin{tabular}{ccc}
\hline Survival time, months & Survival \% & $95 \% \mathrm{Cl}$ \\
\hline 12 & 96 & $94-98$ \\
36 & 77 & $69-85$ \\
60 & 56 & $48-64$ \\
120 & 39 & $29-49$
\end{tabular}

choice to use video-assisted surgery as access for resection of metastatic lesions remains controversial in the literature, even in single lesion cases, because careful palpation of the entire lung parenchyma is impossible and imaging methods are limited in the preoperative evaluation of such lesions. With the increasing sensitivity of imaging methods, especially in cases in which the lesions are located peripherally, we believe that minimally invasive accesses will be more widely in the near future.

The surgical treatment of lung metastases in major studies has followed the principle that all lesions should be completely resected and disease-free margins should be obtained and that resection of lung parenchyma should be as conservative as possible. Among the surgical techniques for excision of lesions, wedge resection and segmentectomy were the most commonly used in various studies, followed, in smaller numbers, by lobectomy and pneumonectomy. ${ }^{(13,14)}$ All these data were extensively reviewed in a recent metaanalysis conducted by Pfannschmidt et al. (2007), in which 20 large studies of surgical treatment of lung metastases from colorectal cancer were compared. ${ }^{(15)}$

Currently, surgery is a significant component of the treatment of lung metastatic disease, and its practice is widely accepted worldwide, resulting in low mortality rates and increased five-year survival rates. In the study by Pfannschmidt et al., ${ }^{(15)}$ the perioperative mortality rate ranged from $0 \%$ to $2.02 \%$, whereas, in the study conducted in Brazil by Younes et al., ${ }^{(8)}$ the rate was $0.4 \%$. These results are in good agreement with the value of 1.9\% found in the present study, showing the safety of the method.

The overall survival rate at 60 months in our sample, which was approximately 56\%, was found to be similar to those reported in the metaanalysis by Pfannschmidt et al., which were as high as $62.7 \%$ also at five years. ${ }^{(15,16)}$ However, since we calculated survival from treatment of the primary tumor, we observed that various 
(A)

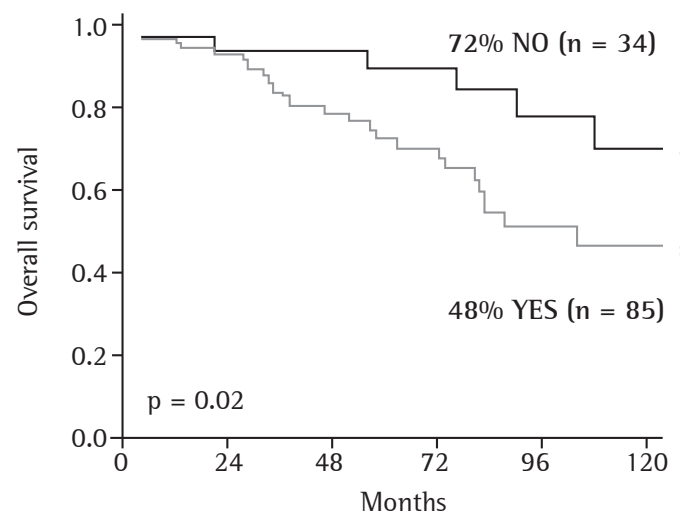

(B)

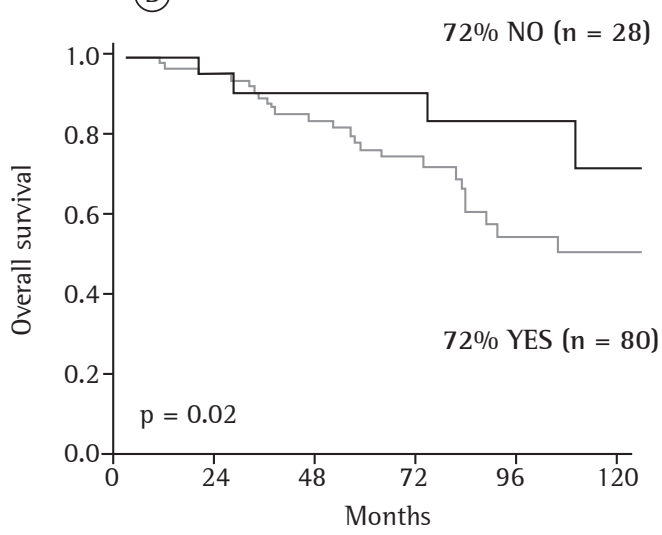

(C)

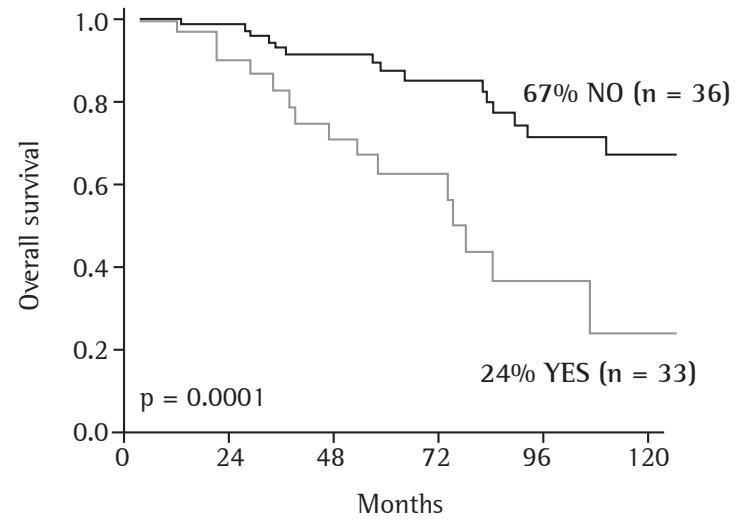

Figure 1 - $\ln A$, overall survival in the groups of patients who underwent and who did not undergo chemotherapy/radiotherapy (CHT/RT) before surgery $(n=119)$. In B, overall survival in the groups of patients who underwent and who did not undergo CHT/RT after surgery $(n=116)$. In C, overall survival in the groups of patients who had and who did not have complications within 30 postoperative days $(n=119)$.

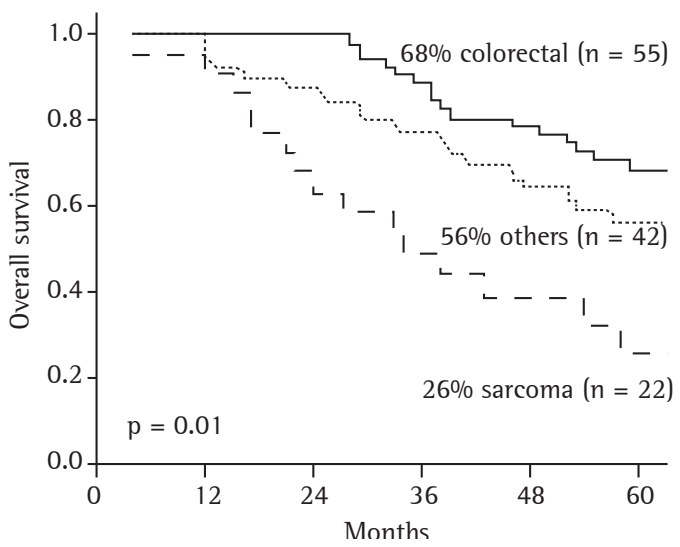

Figure 2 - Overall survival by type of primary tumor.

studies reported much lower results, given that, in them, survival was calculated from resection of the metastasis. For instance, in the study by
Younes et al., ${ }^{(8)}$ survival at 60 months ranged from $10 \%$ to $40 \%$, depending on the primary tumor site.

The prevalence of colorectal cancer as the site of origin of the lung metastases $(47.9 \%$ in our study) led us to perform a separate analysis of overall survival in the patients with this type of cancer as compared with those with musculoskeletal cancer and those with cancer in other anatomical sites. We found that the patients with colorectal cancer had the best survival at 60 months (68\%), whereas those with musculoskeletal cancer had the worst survival (26\%). The vast majority of studies have investigated disease secondary to colorectal cancer only and reported rates of overall survival at 60 months that range from $24.0 \%$ to $62.7 \%$. $(11,16)$ Therefore, we believe that further studies comparing treatment of lung metastases from colorectal cancer with that of lung metastases 
from cancer in other anatomical sites that are less common are needed in order to determine with accuracy the true impact and benefits of this treatment option for specific groups.

In our study, survival at 60 months in the patients who had up to 6 lesions resected ranged from $60 \%$ to $76 \%$, whereas, in those who had more than 7 nodules resected, survival at 60 months dropped to $13 \%$. Most studies have evaluated survival by stratifying patients based on the presence of one resected lesion or multiple resected lesions, with better results being found in patients with single lesions. ${ }^{(8,10,14)}$ However, those same authors reviewed controversial results from various studies that did not find significant differences in the survival of patients with multiple nodules, ${ }^{(17,18)}$ and the difference in results may lie in the heterogeneity of the biological behavior of the different histological types of tumors studied, suggesting the need for larger, specific studies of this variable.

Few studies have addressed laterality of lesions at diagnosis of metastasis and the need for more than one surgical procedure to resect the lesions. In our study, we found that 35 patients (29.4\%) were diagnosed with bilateral disease and that 28 underwent more than one surgical procedure ( 1 of whom underwent four surgical procedures). According to the literature, patients undergoing repeat resection of new pulmonary metastatic lesions have increased survival in comparison with those treated with a single surgery (48\% vs. $34 \%)$, ${ }^{(19)}$ which leads us to believe in the benefits of and to continue to recommend surgical treatment of recurrent lesions as long as the patient is clinically fit to undergo the surgical procedure. With regard to the treatment of bilateral lesions, we found that overall survival was 63\% in the patients with bilateral disease at diagnosis and 55\% in those with unilateral disease, i.e., the difference was not statistically significant, which is in agreement with the findings of the few studies that have addressed this issue and highlights the importance of resection in bilateral disease. ${ }^{(8)}$

Another factor that stood out in the analyses of overall survival was the poorer survival of the patients who underwent chemotherapy/ radiotherapy as compared with those who did not. We understand this finding to mean that the need for neoadjuvant and adjuvant treatment indicates disease in more advanced stages and weakness associated with sequential multimodal treatment. However, this finding is in disagreement with the results reported by Younes et al. ${ }^{(8)}$ who found a significant improvement in survival in the group of patients who underwent chemotherapy/ radiotherapy, as well as with the finding of an absence of significant differences between these two groups in the main studies ${ }^{(20-22)}$ reviewed in the meta-analysis by Pfannschmidt, ${ }^{(15)}$ which leads us to agree with the opinion of those authors who claim that the different protocols for the different types of primary tumor may hinder the understanding of the true impact on the survival of patients undergoing complementary treatment.

There have been few studies addressing perioperative complications and survival in this specific group. The study by Younes et al.(8) found an overall rate of complications of 3.2\%. However, there was no definition of the parameters used for classifying these events, nor was there an analysis of survival in this group only. In the present study sample, the rate of (minor and major) complications was $22 \%$, and a Cox analysis confirmed a poor prognosis for this group of patients. Therefore, by considering even minor events (such as air leaks for more than five days) as a potential morbidity, we emphasize the importance of the fact that even these events, alone or in combination, can be predictive of a poor prognosis for the patient.

In conclusion, surgical treatment of lung metastases from different tumor sites is safe and effective, with significant overall survival, especially in patients with a smaller number of lung lesions. Survival was found to be poor in the patients with metastases from sarcomas and in those who underwent neoadjuvant or adjuvant chemotherapy/radiotherapy. Large multicenter prospective studies using better biological and molecular classification should provide a more refined understanding of and new prognostic parameters for these systemic malignant neoplasms.

\section{References}

1. Aberg T, Malmberg KA, Nilsson B, Nöu E. The effect of metastasectomy: fact or fiction? Ann Thorac Surg. 1980;30(4):378-84. http://dx.doi.org/10.1016/ S0003-4975(10)61278-7

2. Weinlechner JD. Tumorenan der brustwand und derenbehand-lung (Resektion der rippen, eroffnung der brusthohle, partielleentfernun der lunge). Wiener Med Wschr. 1882;20:589-91. 
3. Ehrenhaft JL. Pulmonary resections for metastatic lesions. AMA Arch Surg. 1951;63(3):326-36. http:// dx.doi.org/10.1001/archsurg.1951.01250040332007 PMid:14868186

4. Fujisawa T, Yamaguchi Y, Saitoh $Y$, Sekine $Y$, lizasa T, Mitsunaga $S$, et al. Factors influencing survival following pulmonary resection for metastatic colorectal carcinoma. Tohoku J Exp Med. 1996;180(2):153-60. http://dx.doi. org/10.1620/tjem.180.153 PMid:9111764

5. Dellai RCA, Chojniak R, Marques E, Younes RN. Detecção de nódulos pulmonares por tomografia computadorizada em pacientes com metástases pulmonares submetidos à cirurgia. J Pneumol. 1994;20(Suppl 3):28.

6. Thomford NR, Woolner LB, Clagett OT. The surgical treatment of metastatic tumors in the lungs. J Thorac Cardiovasc Surg. 1965;49:357-63. PMid:14265951

7. Morales-Blanhir JE, Palafox Vidal CD, Rosas Romero Mde J, García Castro MM, Londono Villegas A, Zamboni M. Six-minute walk test: a valuable tool for assessing pulmonary impairment. J Bras Pneumol. 2011;37(1):110-7. http://dx.doi.org/10.1590/S1806-37132011000100016 PMid:21390439

8. Younes RN, Haddad F, Ferreira F, Gross JL. Surgical removal of pulmonary metastasis: prospective study in 182 patients [Article in Portuguese]. Rev Assoc Med Bras. 1998;44(3):218-25. PMid:9755551

9. Moore KH, McCaughan BC. Surgical resection for pulmonary metastases from colorectal cancer. ANZ J Surg. 2001;71(3):143-6. http://dx.doi. org/10.1046/j.1440-1622.2001.02057.x

10. Pfannschmidt J, Muley T, Hoffmann H, Dienemann H. Prognostic factors and survival after complete resection of pulmonary metastases from colorectal carcinoma: experiences in 167 patients. J Thorac Cardiovasc Surg. 2003;126(3):732-9. http://dx.doi.org/10.1016/ S0022-5223(03)00587-7

11. Rena O, Casadio C, Viano F, Cristofori R, Ruffini E, Filosso PL, et al. Pulmonary resection for metastases from colorectal cancer: factors influencing prognosis. Twenty-year experience. Eur J Cardiothorac Surg. 2002;21(5):906-12. http://dx.doi.org/10.1016/ S1010-7940(02)00088-X

12. Saito Y, Omiya H, Kohno K, Kobayashi T, Itoi K, Teramachi $\mathrm{M}$, et al. Pulmonary metastasectomy for 165 patients with colorectal carcinoma: A prognostic assessment. J Thorac Cardiovasc Surg. 2002;124(5):1007-13. http:// dx.doi.org/10.1067/mtc.2002.125165 PMid:12407386
13. Toscano E. Tratamento cirúrgico das metástases nodulares do pulmão [thesis]. Rio de Janeiro: Universidade Federal Fluminense; 1991.

14. Rama N, Monteiro A, Bernardo JE, Eugénio L, Antunes MJ. Lung metastases from colorectal cancer: surgical resection and prognostic factors. Eur J Cardiothorac Surg. 2009;35(3):444-9. http://dx.doi.org/10.1016/j. ejcts.2008.10.047 PMid:19136273

15. Pfannschmidt J, Dienemann H, Hoffmann H. Surgical resection of pulmonary metastases from colorectal cancer: a systematic review of published series. Ann Thorac Surg. 2007;84(1):324-38. http://dx.doi.org/10.1016/j. athoracsur.2007.02.093 PMid:17588454

16. Ike H, Shimada H, Ohki S, Togo S, Yamaguchi S, Ichikawa Y. Results of aggressive resection of lung metastases from colorectal carcinoma detected by intensive follow-up. Dis Colon Rectum. 2002;45(4):468-73; discussion 473-5. http://dx.doi.org/10.1007/s10350-004-6222-0 PMid:12006927

17. Inoue M, Ohta M, luchi K, Matsumura A, Ideguchi K, Yasumitsu T, et al. Benefits of surgery for patients with pulmonary metastases from colorectal carcinoma. Ann Thorac Surg. 2004;78(1):238-44. http://dx.doi. org/10.1016/j.athoracsur.2004.02.017 PMid:15223436

18. Monteiro A, Arce N, Bernardo J, Eugénio L, Antunes MJ. Surgical resection of lung metastases from epithelial tumors. Ann Thorac Surg. 2004;77(2):431-7. http://dx.doi. org/10.1016/j.athoracsur.2003.06.012 PMid:14759411

19. Groeger AM, Kandioler MR, Mueller MR, End A, Eckersberger F, Wolner E. Survival after surgical treatment of recurrent pulmonary metastases. Eur J Cardiothorac Surg. 1997;12:703-5. http://dx.doi.org/10.1016/ S1010-7940(97)00239-X

20. Mauro Rossi B, Lopes A, Paulo Kowalski L, de Oliveira Regazzini RC. Prognostic factors in 291 patients with pulmonary metastases submitted to thoracotomy. Sao Paulo Med J. 1995;113(3):910-6. http://dx.doi.org/10.1590/ S1516-31801995000300005 PMid:8728726

21. Kanemitsu Y, Kato T, Hirai T, Yasui K. Preoperative probability model for predicting overall survival after resection of pulmonary metastases from colorectal cancer. Br J Surg. 2004;91(1):112-20. http://dx.doi.org/10.1002/ bjs.4370 PMid:14716804

22. Lee WS, Yun SH, Chun HK, Lee WY, Yun HR, Kim J, et al. Pulmonary resection for metastases from colorectal cancer: prognostic factors and survival. Int J Colorectal Dis. 2007;22(6):699-704. http://dx.doi.org/10.1007/ s00384-006-0218-2 PMid:17109105 


\section{About the authors}

\section{Giana Balestro Poletti}

Thoracic Surgeon. Universidade Estadual de Campinas - Unicamp, State University at Campinas - Hospital de Clínicas, Campinas, Brazil.

\section{Ivan Felizardo Contrera Toro}

Professor. Department of Thoracic Surgery, Universidade Estadual de Campinas - Unicamp, State University at Campinas - School of Medical Sciences, Campinas, Brazil.

\section{Thais Ferreira Alves}

Medical Student. Universidade Estadual de Campinas - Unicamp, State University at Campinas - School of Medical Sciences, Campinas, Brazil.

\section{Eliana Cristina Martins Miranda}

Data and Statistics Analyst. Blood Bank, Universidade Estadual de Campinas - Unicamp, State University at Campinas - School of Medical Sciences, Campinas, Brazil.

\section{José Cláudio Teixeira Seabra}

Attending Physician. Department of Thoracic Surgery, Universidade Estadual de Campinas - Unicamp, State University at Campinas

- School of Medical Sciences, Campinas, Brazil.

\section{Ricardo Kalaf Mussi}

Professor and Coordenator. Department of Thoracic Surgery, Universidade Estadual de Campinas - Unicamp, State University at Campinas - School of Medical Sciences, Campinas, Brazil. 